\title{
The Use of Artificial Neural Networks (ANNs) in Aquatic Ecology
}

\author{
Antoni Quetglas, Francesc Ordines and Beatriz Guijarro \\ Instituto Español de Oceanografía, Centre Oceanogràfic de les Balears \\ Spain
}

\section{Introduction}

Complex network systems are pervasive in life sciences at all levels, from molecules and genes to organisms and ecosystems. All these systems are characterized by being constituted of numerous components or nodes (molecules, genes, cells, tissues, organisms), which are interconnected by many links in an intricate tangle, just as biological neural networks consist of many interacting neurons (Fig. 1). Apart from its structural complexity, complex networks are inherently difficult to understand because interactions are non-linear, distributed non-randomly, and are adaptive, that is, changing continuously in response to the state of the system itself (Strogatz, 2001; Pascual \& Dunne, 2006). Understanding the functioning of these systems consisting of a large number of strongly interacting units represents therefore a major endeavour for biologists and ecologists.

As complex networks, ecosystems are non-linear systems constituted by countless interacting pieces, both biotic and abiotic, constituting the entangled web of life. In a world threatened by global environmental problems such as biodiversity loss, climate change, fishing overexploitation or pollution, ecologists are challenged by the need to understand and predict the dynamics of ecosystems as never before. Along with the complexity of ecological systems, ecologists are also faced with a huge amount of information that recent advances in data collection technology such as remote sensing have produced. To cope with the ecosystem complexity and large data sets currently available, ecologists nowadays have the opportunity to use machine-like learning techniques such as the artificial neural networks (ANNs).

As their name implies, ANNs are biologically inspired and were initially intended to mimic the neural activity in the human or animal brains (Garson, 1991; Goh, 1995; Stern, 1996). ANNs models are based on the same learning processes as the animal brain, which gathers information from the environment (input data) and gives an answer (output data) after using learned training algorithms. However, given that the architecture and dynamics of the animal brain is exceedingly complex, even the most elaborated ANN models are mere caricatures of the biological brain. Although the original works on ANNs date back to the forties (McCulloch \& Pitts, 1943; Pitts \& McCulloch, 1947), they not became really popular until the eighties after the work of the physicist John Hopfield. Hopfield (1982) introduced an oversimplified neural network, comprising a set of fully connected binary units, as a metaphor of neural computation. The most remarkable feature of this model was that it could learn by association and was quiet insensitive to noise. This capacity to recognize previously learned patterns, which was thought to be an exclusive property of brains, is precisely what the Hopfield model does (Solé \& Goodwin, 2000). 


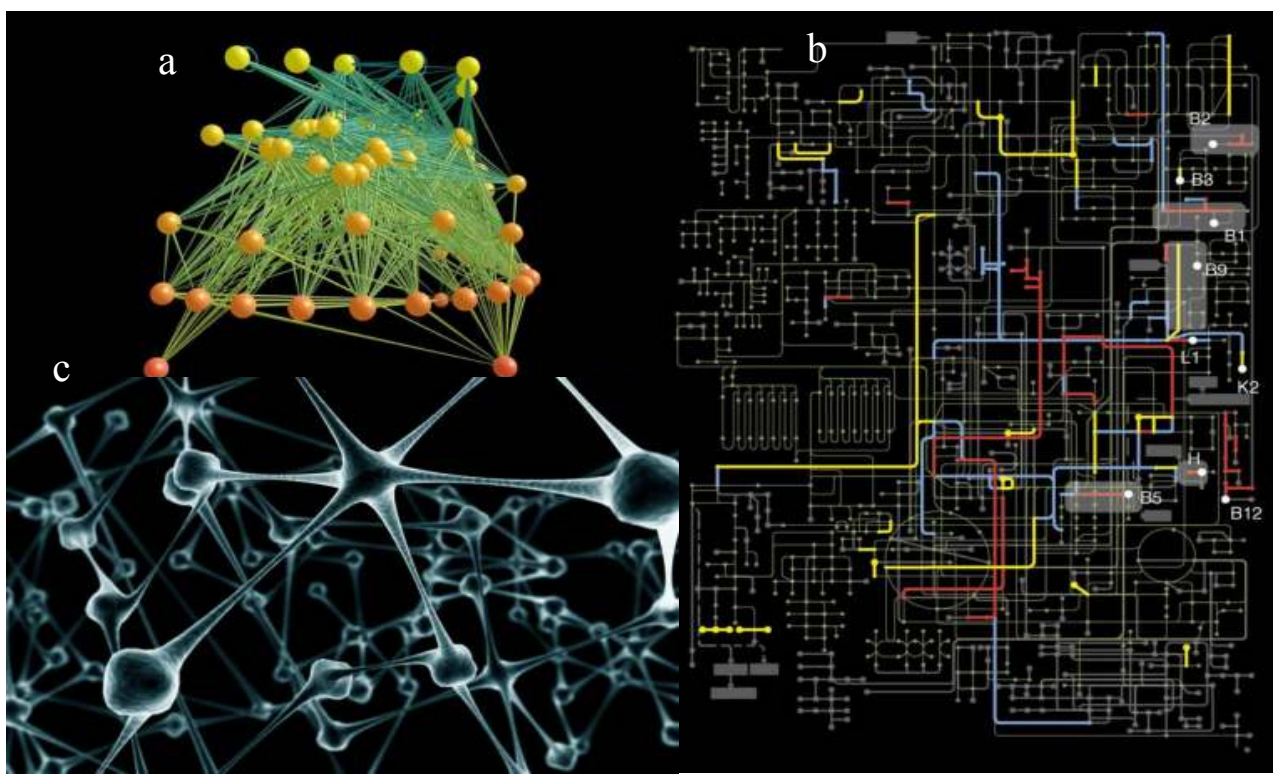

Fig. 1. Examples of complex networks in living systems: a) Caribbean Reef food web. The image is organized vertically, with basal species in the bottom, top predators above and intermediate species in between. b) Metabolic pathways of $H$. sapiens and two bacteria present in the human intestine and considered key commensals in the human intestinal microflora. c) Depiction of highly interconnected neurons in the animal brain.

The first applications of ANNs did not appear until the early 1990s after the publication of the error back-propagation algorithm (Rumelhart et al., 1986). ANNs have enjoyed explosive growth since then and have been successfully applied across a broad range of scientific domains, as shows this book and other previous works (e.g. Bishop, 1995; Sarle, 1997; Picton, 2000). However, a review of the literature reveals only a modest use of these approaches in ecology as compared to other disciplines, which could be related to the lack of the computational background necessary to implement these methods among ecologists (Olden et al., 2008). In spite of these limitations, ecologists have nowadays good comprehensive overviews of ANN applications in ecological sciences, such as the books of Fielding (1999), Lek \& Guegan (2000), Lek et al. (2005) and Recknagel (2006). These books adds to an ever-increasing number of papers being published during the last years in many scientific journals, among which is worth highlighting some specialized ones such as Ecological Modelling (www.elsevier.com/locate/ecolmodel) and the recently launched Ecological Informatics (www.elsevier.com/locate/ecolinf).

In this chapter we review the use of ANNs in marine and freshwater ecology, including fisheries science, during the 1990s and 2000s. Such review is restricted to works published in international journals and is not intended to be exhaustive but simply to familiarize the reader with the capabilities and practical applications of ANNs in aquatic ecology. Detailed insights on the methodology are not given because those general aspects of ANNs are already discussed either on other chapters of this book or in other works (e.g. Bishop, 1995; Picton, 2000), and those issues specific to ecological applications have been reviewed elsewhere (e.g. Maier \& Dandy, 2000; Lek \& Guegan, 2000; Ozesmi et al., 2006). 


\section{Handling ecological data with ANNs}

The characteristics of ecological data are quite different from those data handled by sciences traditionally considered harder than ecology like mathematics or physics. Ecological data are generally bulky, non-linear and highly complex, showing noise, redundancy, internal relations and outliers (Park et al., 2003a). In many cases researchers have rather unbalanced data sets, such as in community or taxonomical studies when data contain both a lot of uncommon, or not present species, and a reduced number of very abundant species. Traditionally, multivariate analyses of ecological data have been done using conventional techniques based on linear principles, such as multiple regression or discriminant analysis. However, relationships between variables in ecology are often non-linear or even unknown, which demands non-linear transformations to improve the results. Despite transformations by logarithmic, power or exponential functions, results are not satisfactory in many cases (Lek et al., 1996b; Brosse et al., 1999). In this respect ANNs constitute a promising alternative approach since they are powerful tools that manage large, complex datasets well, and are especially suitable when relationships between variables are non-linear or unknown (Lek et al., 1996b). This idea that neural networks do not require distributional assumptions is fully shared by ecologists and is generally claimed as the most important advantage of ANNs over classical statistical models. In fact, Maier \& Dandy (2000) recommend that the primary focus should be on achieving good results, rather than statistical optimality, as this is one of the features that has attracted water resources modellers to ANNs in the first place. According to Sarle (1997), however, ANNs are subjected to the same assumptions as statistical models, and the explanation is simply that, whereas statisticians are concerned about the implications of those assumptions, many neural network users ignore them.

Formerly, ANNs were compared to "black boxes" because they always give an answer (output) when they are fed with data (input), although the internal processes taking place inside the network were not clearly understood. This prevented knowing the contribution of the independent variables in the prediction process, which is a major concern to ecologists, who are always interested in uncovering the causal relationships driving ecological phenomena (Olden \& Jackson, 2002). The "black box" term is no longer a suitable term, since recent advances in the field of environmental sciences have provided a set of techniques to determine the relative importance of each input variable. These techniques include sensitivity analyses (Scardi, 1996; Lek et al., 1996a; Recknagel et al., 1997), input variable relevancies and neural interpretation diagrams (Ozesmi \& Ozesmi, 1999), randomization tests of significance (Olden, 2000; Olden \& Jackson, 2002), and partial derivatives (Dimopoulos et al., 1999; Reyjol et al., 2001; Gevrey et al., 2006). All these approaches are based on the fact that the contribution of each independent variable depends on the magnitude and direction of the connection weights between neurons (Olden et al., 2008). Good examples of papers dealing with the performance of several of these methods are Olden \& Jackson (2002) and Gevrey et al. (2003). Olden \& Jackson (2002) reviewed both qualitative and quantitative algorithms, but also described a randomization procedure for testing the statistical significance of the input variables. Gevrey et al. (2003) compared up to seven approaches and found that the partial derivatives method was the most useful in an empirical example predicting the density of brown trout spawning redds using habitat characteristics.

There are many different types of ANNs, which are classified according to their learning process and learning algorithm (Sarle, 1997). In supervised learning, the known target values are given to the ANN during training, after which the network is tested using exclusively the input values. In unsupervised learning, the target values are not provided to 


\begin{tabular}{|c|c|c|c|c|}
\hline $\mathrm{N}$ & Reference & $\begin{array}{l}\text { Type of } \\
\text { ANN }\end{array}$ & $\begin{array}{l}\text { Dependent } \\
\text { variables }\end{array}$ & Independent variables \\
\hline 1 & Xu et al. (2005) & BRBPNN & $\begin{array}{l}\text { Algal } \\
\text { abundance (1) }\end{array}$ & $\begin{array}{l}\text { Environmental } \\
\text { variables (3-5) }\end{array}$ \\
\hline 2 & Park et al. (2003b) & $\mathrm{CPN}$ & Fish richness (1) & $\begin{array}{l}\text { Environmental } \\
\text { variables (34) }\end{array}$ \\
\hline 3 & Jeong et al. (2008a) & TARNN & Algal biomass (1) & $\begin{array}{l}\text { Algal } \\
\text { biomass (1) }\end{array}$ \\
\hline 4 & Palmer et al. (2009) & $\begin{array}{l}\text { GRNN, } \\
\text { MLP }\end{array}$ & $\begin{array}{l}\text { Fishing } \\
\text { strategies (4) }\end{array}$ & Fish catches $(33,6)$ \\
\hline 5 & Iglesias et al. (2004) & $\begin{array}{l}\text { FNN, } \\
\text { MLP }\end{array}$ & Fish landings (1) & $\begin{array}{l}\text { Environmental } \\
\text { variables (6) }\end{array}$ \\
\hline 6 & Scardi (1996) & MLP & $\begin{array}{l}\text { Algal } \\
\text { abuncance (1) }\end{array}$ & $\begin{array}{l}\text { Environmental } \\
\text { variables }(3,4)\end{array}$ \\
\hline 7 & $\begin{array}{l}\text { Scardi \& Harding } \\
(1999)\end{array}$ & MLP & $\begin{array}{l}\text { Algal } \\
\text { abundance (1) }\end{array}$ & $\begin{array}{l}\text { Environmental } \\
\text { variables (12) }\end{array}$ \\
\hline 8 & Scardi (2001) & MLP & $\begin{array}{l}\text { Algal } \\
\text { abundance (1) }\end{array}$ & $\begin{array}{l}\text { Environmental } \\
\text { variables (11) }\end{array}$ \\
\hline 9 & $\begin{array}{l}\text { Wilson \& Recknagel } \\
(2001)\end{array}$ & MLP & $\begin{array}{l}\text { Algal } \\
\text { abundance (1) }\end{array}$ & $\begin{array}{l}\text { Environmental } \\
\text { variables }(4,5)\end{array}$ \\
\hline 10 & Recknagel et al. (1997) & MLP & $\begin{array}{l}\text { Algal } \\
\text { abundance (10) }\end{array}$ & $\begin{array}{l}\text { Environmental } \\
\text { variables }(7,10,11)\end{array}$ \\
\hline 11 & $\begin{array}{l}\text { Ozesmi \& Ozesmi } \\
(1999)\end{array}$ & MLP & $\begin{array}{l}\text { Bird nesting } \\
\text { probability }(1,3)\end{array}$ & $\begin{array}{l}\text { Environmental } \\
\text { variables (6) }\end{array}$ \\
\hline 12 & Manel et al. (1999) & MLP & Bird occurrence (1) & $\begin{array}{l}\text { Environmental } \\
\text { variables (32) }\end{array}$ \\
\hline 13 & Fang et al. (2009) & MLP & Bird richness (1) & $\begin{array}{l}\text { Environmental } \\
\text { variables (4) }\end{array}$ \\
\hline 14 & Dedecker et al. (2005) & MLP & $\begin{array}{l}\text { Crustacean } \\
\text { density (1) }\end{array}$ & $\begin{array}{l}\text { Environmental } \\
\text { variables (24) }\end{array}$ \\
\hline 15 & Mouton et al. (2010) & MLP & $\begin{array}{l}\text { Crustacean } \\
\text { density (1) }\end{array}$ & $\begin{array}{l}\text { Environmental } \\
\text { variables (24) }\end{array}$ \\
\hline 16 & $\begin{array}{l}\text { Huse \& Gjosaeter } \\
(1999)\end{array}$ & MLP & Fish abundance (1) & $\begin{array}{l}\text { Environmental } \\
\text { variables (6) }\end{array}$ \\
\hline 17 & Joy \& Death (2004) & MLP & $\begin{array}{l}\text { Fish and } \\
\text { crustacean } \\
\text { occurrence (14) }\end{array}$ & $\begin{array}{l}\text { Environmental } \\
\text { variables (31) }\end{array}$ \\
\hline 18 & Dagorn et al. (1997) & MLP & Fish behaviour (1) & $\begin{array}{l}\text { Environmental } \\
\text { variables (7) }\end{array}$ \\
\hline 19 & $\begin{array}{l}\text { Huse \& Ottersen } \\
(2003)\end{array}$ & MLP & Fish density (1) & $\begin{array}{l}\text { Environmental } \\
\text { variables (10) }\end{array}$ \\
\hline
\end{tabular}




\begin{tabular}{|c|c|c|c|c|}
\hline $\mathrm{N}$ & Reference & $\begin{array}{l}\text { Type of } \\
\text { ANN }\end{array}$ & $\begin{array}{l}\text { Dependent } \\
\text { variables }\end{array}$ & Independent variables \\
\hline 20 & Baran et al. (1996) & MLP & Fish density (1) & $\begin{array}{l}\text { Environmental } \\
\text { variables (11) }\end{array}$ \\
\hline 21 & Brosse et al. (1999) & MLP & Fish density (1) & $\begin{array}{l}\text { Environmental } \\
\text { variables (8) }\end{array}$ \\
\hline 22 & Gevrey et al. (2003) & MLP & Fish density (1) & $\begin{array}{l}\text { Environmental } \\
\text { variables (10) }\end{array}$ \\
\hline 23 & Lae et al. (1999) & MLP & Fish density (1) & $\begin{array}{l}\text { Environmental } \\
\text { variables }\end{array}$ \\
\hline 24 & Lek et al. (1996b) & MLP & Fish density (1) & $\begin{array}{l}\text { Environmental } \\
\text { variables (11) }\end{array}$ \\
\hline 25 & $\begin{array}{l}\text { Gutierrez-Estrada et al. } \\
\text { (2009) }\end{array}$ & MLP & Fish landings (1) & $\begin{array}{l}\text { Environmental } \\
\text { variables (18) }\end{array}$ \\
\hline 26 & Olden et al. (2006) & MLP & $\begin{array}{l}\text { Fish } \\
\text { occurrence (16) }\end{array}$ & $\begin{array}{l}\text { Environmental } \\
\text { variables (24) }\end{array}$ \\
\hline 27 & Maravelias et al. (2003) & MLP & Fish occurrence (2) & $\begin{array}{l}\text { Environmental } \\
\text { variables (5) }\end{array}$ \\
\hline 28 & Mastrorillo et al. (1997) & MLP & Fish occurrence (2) & $\begin{array}{l}\text { Environmental } \\
\text { variables (10) }\end{array}$ \\
\hline 29 & Olden (2003) & MLP & $\begin{array}{l}\text { Fish } \\
\text { occurrence (27) }\end{array}$ & $\begin{array}{l}\text { Environmental } \\
\text { variables (9) }\end{array}$ \\
\hline 30 & Chen \& Hare (2006) & MLP & $\begin{array}{l}\text { Fish recruitment } \\
\text { (1) }\end{array}$ & $\begin{array}{l}\text { Environmental } \\
\text { variables (2) }\end{array}$ \\
\hline 31 & Ibarra et al. (2003) & MLP & Fish richness (1) & $\begin{array}{l}\text { Environmental } \\
\text { variables (5) }\end{array}$ \\
\hline 32 & Beauchard et al. (2003) & MLP & $\begin{array}{l}\text { Invertebrate } \\
\text { richness (1) }\end{array}$ & $\begin{array}{l}\text { Environmental } \\
\text { variables (7) }\end{array}$ \\
\hline 33 & Dedecker et al. (2004) & MLP & $\begin{array}{l}\text { Invertebrates } \\
\text { occurrence (1) }\end{array}$ & $\begin{array}{l}\text { Environmental } \\
\text { variables (15) }\end{array}$ \\
\hline 34 & $\begin{array}{l}\text { Engelhard \& Heino } \\
(2004)\end{array}$ & MLP & $\begin{array}{l}\text { Age } \\
\text { at maturation (1) }\end{array}$ & $\begin{array}{l}\text { Annual } \\
\text { growth layers (3-9) }\end{array}$ \\
\hline 35 & Engelhard et al. (2003) & MLP & $\begin{array}{l}\text { Age } \\
\text { at maturation (1) }\end{array}$ & $\begin{array}{l}\text { Annual } \\
\text { growth layers (3-9) }\end{array}$ \\
\hline 36 & Dreyfus-Leon (1999) & MLP & $\begin{array}{l}\text { Fishermen } \\
\text { strategies }(3,16)\end{array}$ & Fishing variables $(9,20)$ \\
\hline 37 & Newbury et al. (1995) & MLP & Fish density (10) & $\begin{array}{l}\text { Frequency } \\
\text { image data (51) }\end{array}$ \\
\hline 38 & Power et al. (2005) & MLP & Fishing location (3) & Parasite abundances (5) \\
\hline 39 & $\begin{array}{l}\text { Haralabous \& } \\
\text { Georgakarakos (1996) }\end{array}$ & MLP & $\begin{array}{l}\text { Fish } \\
\text { identification (3) }\end{array}$ & $\begin{array}{l}\text { School } \\
\text { descriptors (25) }\end{array}$ \\
\hline
\end{tabular}




\begin{tabular}{|c|c|c|c|c|}
\hline $\mathrm{N}$ & Reference & $\begin{array}{l}\text { Type of } \\
\text { ANN }\end{array}$ & $\begin{array}{l}\text { Dependent } \\
\text { variables }\end{array}$ & Independent variables \\
\hline 40 & Song et al. (2006) & SOM & \multicolumn{2}{|c|}{ Sampling sites; invertebrates assemblages } \\
\hline 41 & Jeong et al. (2008b) & SOM & \multicolumn{2}{|c|}{ Sampling sites } \\
\hline 42 & Brosse et al. (2001) & SOM & \multicolumn{2}{|c|}{ Fish assemblages } \\
\hline 43 & Hyun et al. (2005) & SOM & \multicolumn{2}{|c|}{ Fish assemblages } \\
\hline 44 & Zhu et al. (2006) & SOM & \multicolumn{2}{|c|}{ Fish genetic structure } \\
\hline 45 & Chon et al. (1996) & SOM & \multicolumn{2}{|c|}{ Invertebrates assemblages } \\
\hline 46 & Cereghino et al. (2001) & SOM & \multicolumn{2}{|c|}{ Invertebrates assemblages } \\
\hline 47 & Park et al. (2006) & SOM & \multicolumn{2}{|c|}{ Invertebrates assemblages } \\
\hline 48 & Cho et al. (2009) & SOM & \multicolumn{2}{|c|}{ Sampling sites } \\
\hline 49 & $\begin{array}{l}\text { Hardman-Mountford } \\
\text { et al. (2003) }\end{array}$ & SOM & \multicolumn{2}{|c|}{ Sea level variations } \\
\hline 50 & Park et al. (2003a) & $\begin{array}{l}\text { SOM, } \\
\text { MLP }\end{array}$ & \multicolumn{2}{|c|}{$\begin{array}{l}\text { SOM: sampling sites; } \\
\text { MLP: invertebrate assemblages }\end{array}$} \\
\hline 51 & Gevrey et al. (2004) & $\begin{array}{l}\text { SOM, } \\
\text { MLP }\end{array}$ & \multicolumn{2}{|c|}{$\begin{array}{l}\text { SOM: sampling sites; } \\
\text { MLP: diatom assemblages }\end{array}$} \\
\hline 52 & Tison et al. (2007) & $\begin{array}{l}\text { SOM, } \\
\text { MLP }\end{array}$ & \multicolumn{2}{|c|}{$\begin{array}{l}\text { SOM: sampling sites; } \\
\text { MLP: diatom assemblages }\end{array}$} \\
\hline 53 & Park et al. (2004) & $\begin{array}{l}\text { SOM, } \\
\text { ART }\end{array}$ & \multicolumn{2}{|c|}{ Invertebrates assemblages } \\
\hline 54 & Chon et al. (2000) & $\begin{array}{l}\text { SOM, } \\
\text { ART }\end{array}$ & \multicolumn{2}{|c|}{ Invertebrates assemblages } \\
\hline
\end{tabular}

Table 1. List of papers with applications of ANNs in aquatic ecology: source, type of ANN, dependent variable and independent variables. In the case of MLPs, the numbers into brackets are the number of input neurons (independent variables) or output neurons (dependent variables). In the case of SOMs, the single cell under the dependent and independent variable headers contains the type of data that was patternized by means of the SOM. In those papers (50-53) using unsupervised (SOM) followed by supervised neural networks (MLP), the variable to be predicted by the MLP it is also shown.

the network, which usually performs some kind of dimensionality reduction or clustering. Depending on the existence or not of cycles in the connections between nodes the networks are classified as feedback, or recurrent ANNs, and feed-forward ANNs. Up to now, the most popular ANNs in ecological applications are the multilayer perceptron (MLP) with backpropagation algorithm and the Kohonen network or self-organizing map (SOM), although examples of other family of models have also been applied. In this work, for instance, we have reviewed a total of 54 papers dealing with applications of ANNs in the field of marine and freshwater ecology (Table 1): the MLP and the SOM were used in 39 and 15 cases, respectively, whereas other types of networks (see Section 8) were only used in 7 cases. In later sections, we give a succinct description of these methods and revise their main applications among researchers working on aquatic ecology. 


\section{Development of ANN models}

Several papers have reviewed the use of ANNs in ecological applications and summarized both the main drawbacks in the available works and the main methodological issues that should be considered in the development of new models (Maier \& Dandy, 2000; Maier \& Dandy, 2001; Ozesmi et al., 2006). Maier \& Dandy (2000) analysed different modelling issues of ANNs for the prediction and forecasting of water resources variables by reviewing up to 43 papers published until the end of 1998. One year later, the same authors (Maier \& Dandy, 2001) published a systematic approach to the development of ANNs for environmental studies, which was intended to act as a guide for users of feed-forward, back-propagation ANNs. Ozesmi et al. (2006) also analysed different methodological issues in building, training and testing ANNs in ecological applications and made useful suggestions on its use. More recently, Suryanarayana et al. (2008) performed a thorough revision of the use of neural networks in fisheries research; after a brief description of ANNs the authors reviewed their applications in forecasting, classification, distribution and fisheries management since 1978 (97 and 103 papers during 1978-1999 and 2000-2006, respectively). What follows is an extract from all these papers; although they focused on the MLP, most of their recommendations also apply to other types of ANNs.

In general the modelling process is not described clearly, what prevents to assess the optimality of the results and the comparison between models. The major problem was overtraining (over-fitting), which could be avoided by limiting the complexity of the model. To do so, there are some rules of thumb, such as using at least 10 times the number of samples as parameters in the model (Burnham \& Anderson, 2002). Another important concern refers to the lack of independent data sets, what makes that some data are used both in the training and testing processes. Given that it is difficult or costly to obtain a sufficient number of replicates in ecological studies, examples with independent test data sets are rather scarce. As an alternative, researchers use different methodologies to create a testing data set such as jack-knife or cross-validation. Finally, the choice of the type of model, its architecture and the internal parameters (e.g. number of hidden layers) are also poorly described in most cases.

In order to avoid all these concerns and to optimize the performance of the models, specialists recommend considering the following methodological issues. First, the input variables should be standardized and, although there is no need to transform data, it is recommended in order to remove trends and heteroscedasticity. Next, appropriate input variables should be determined with the aid of a priori knowledge, by using analytical techniques or a stepwise model-building approach. Learn rate and weight range should also be determined since these network parameters influence the performance of the model by affecting the weights. The choice of adequate network geometry involves the optimization of the architecture, the number of hidden layers and number of hidden neurons. Although there are guidelines in the literature to obtain optimal network geometries, for each application it has been done traditionally by a process of trial and error. To compare the performance of models created with the same data set it is recommended the use of criteria such as the Akaike Information Criteria (AIC). Finally, model performance should be assessed using independent data sets to ensure that the results obtained are valid, since the real model test does not involve the training but the testing phase. 


\begin{tabular}{|c|c|c|c|c|c|}
\hline $\mathrm{N}$ & Reference & $\begin{array}{l}\text { Type of } \\
\text { ANN }\end{array}$ & $\begin{array}{c}\text { ANN } \\
\text { Performance }\end{array}$ & $\begin{array}{l}\text { Type of } \\
\text { MSM }\end{array}$ & $\begin{array}{c}\text { MSM } \\
\text { Performance }\end{array}$ \\
\hline 1 & $\begin{array}{c}\text { Haralabous \& } \\
\text { Georgakarakos (1996) }\end{array}$ & MLP & $95.92 \%$ & DA & $89.29 \%$ \\
\hline 2 & Baran et al. (1996) & MLP & $0.92,0.93$ & GLM & $0.54,0.69$ \\
\hline 3 & Lek et al. (1996b) & MLP & 0.96 & MLR & $0.471,0.72^{2}$ \\
\hline 4 & Brosse et al. (1999) & MLP & $66,97 \%$ & MLR & $46,95 \%$ \\
\hline 5 & Lae et al. (1999) & MLP & $0.95,0.83$ & MLR & $0.62^{1}, 0.81^{2}$ \\
\hline 6 & Gevrey et al. (2003) & MLP & $0.75,0.76$ & MLR & 0.47 \\
\hline 7 & Ibarra et al. (2003) & MLP & $0.55,0.82$ & MLR & $0.33,0.72$ \\
\hline 8 & $\begin{array}{c}\text { Engelhard et al. } \\
(2003)\end{array}$ & MLP & $66.6 \%$ & DA & $68.0 \%$ \\
\hline 9 & $\begin{array}{l}\text { Engelhard \& Heino } \\
\qquad(2004)\end{array}$ & MLP & 0.976 & DA & 0.985 \\
\hline 10 & $\begin{array}{c}\text { Maravelias et al. } \\
\text { (2003) }\end{array}$ & MLP & $83.3,85.6 \%$ & DA & $49.5,83.3 \%$ \\
\hline 11 & $\begin{array}{c}\text { Mastrorillo et al. } \\
\text { (1997) }\end{array}$ & MLP & $82.1,90.1 \%$ & DA & $62.5,78.0 \%$ \\
\hline 12 & Fang et al. (2009) & MLP & 0.28 & MLR & 0.28 \\
\hline 13 & $\begin{array}{c}\text { Gutierrez-Estrada et } \\
\text { al. (2009) }\end{array}$ & MLP & $0.98^{\mathrm{t}}, 0.92^{\mathrm{s}}$ & $\begin{array}{l}\text { MLR, } \\
\text { GAM }\end{array}$ & $\begin{array}{l}\text { MLR: } 0.69 \mathrm{t}, 0.70^{\mathrm{s}} \\
\text { GAM: } 0.87 \mathrm{t}, 0.86^{\mathrm{s}}\end{array}$ \\
\hline 14 & Jeong et al. (2008a) & TARNN & $\begin{array}{l}0.97,0.98^{\mathrm{t}} \\
0.94,0.92^{\mathrm{s}} \\
\end{array}$ & $\begin{array}{l}\text { SARIMA, } \\
\text { SES }\end{array}$ & $\begin{array}{c}\text { SARIMA: } 0.54^{\mathrm{t}}, 0.28^{\mathrm{s}} \\
\text { SES: } 0.88^{\mathrm{t}}, 0.38^{\mathrm{s}} \\
\end{array}$ \\
\hline 15 & Olden et al. (2006) & MLP & $66,91 \%$ & $\begin{array}{c}\text { MDA, } \\
\text { LOG }\end{array}$ & $\begin{array}{c}\text { MDA: } 46 \%, \\
\text { LOG: } 83 \% \\
\end{array}$ \\
\hline 16 & Power et al. (2005) & MLP & $92,94 \%$ & $\begin{array}{l}\text { DA, } \\
\text { QDA, } \\
\text { KKN }\end{array}$ & $\begin{array}{c}\text { DA: } 93,94 \% \\
\text { QDA: } 92,93 \% \\
\text { KNN: } 94,96 \%\end{array}$ \\
\hline 17 & Lae et al. (1999) & MLP & $0.95^{\mathrm{t}}, 0.83^{\mathrm{s}}$ & MLR & 0.81 \\
\hline 18 & Scardi (1996) & MLP & $0.90,0.954$ & MLR & $0.27^{3}, 0.74^{4}$ \\
\hline
\end{tabular}

Table 2. Performance of ANNs compared to classical multivariate statistical models (MSM) in aquatic ecological applications. The indexes used to calculate the performance are not specified (mainly determination coefficient and percentage of correctly classified instances) but are the same in each reference for comparisons. When available, results are given for the training (t) and testing (s); numbers in superscripts refer to raw (1) vs. transformed (2) data, and single (3) vs. composite (4) linear model. MLR: multiple linear regression; GLM: generalized linear models; DA: discriminant analysis; GAM: generalized additive models; SARIMA: seasonal auto-regressive integrated moving average; SES: simple exponential smoothing; MDA: multiple discriminant analysis; LOG: logistic regression analysis; QDA: quadratic discriminant analysis; KKN: $k$-nearest neighbour classification. 


\section{ANNs vs. multivariate analyses}

Several studies indicate that ANNs are identical or similar to different standard statistical models. Changing some parameters of the network structure, such as the transfer function or the number of hidden nodes, gives rise to existing models. Feed-forward networks with no hidden layer, for instance, are basically generalized linear models, whereas Kohonen SOMs are discrete approximations to principal curves and surfaces (Sarle, 1997). The training and learning phases in neural networks are not different from the parameter estimation phase in conventional statistical models (Maier \& Dandy, 2000).

Many of the published works on ANNs in marine and freshwater ecology compare this modelling method with classical multivariate statistical procedures, such as multiple linear regression (MLR) or discriminant analysis (DA). In all cases, these works found that ANNs either clearly outperformed (e.g. Baran et al., 1996; Lek et al., 1996b; Mastrorillo et al., 1997; Brosse et al., 1999) or at least performed as well (e.g. Engelhard et al., 2003; Engelhard \& Heino, 2004; Power et al., 2005; Fang et al., 2009) as classical techniques (Table 2). Differences between methods are very important in some applications. Analysing the relationships between density of trout spawning sites and habitat characteristics, for instance, Lek et al. (1996) obtained values of determination coefficients of 0.96 for the MLP and 0.47 (raw data) or 0.72 (transformed data) for the MLR. In a similar study, Gevrey et al. (2003) also found important differences, about 0.77 for MLP and 0.47 for MLR. However, the highest differences were obtained by Jeong et al. (2008a) comparing a type of ANN known as temporal autoregressive recurrent neural network (TARNN) and two model types based on root mean square error (RMSE), seasonal auto-regressive integrated moving average (SARIMA) and simple exponential smoothing (SES).

The work of Manel et al. (1999) exemplifies the concerns raised by most researchers when ANNs were not more performant than linear models. In their analysis of a river bird species distribution, substitute major conclusion was that ANN does not currently have major advantages over logistic regression and DA in the particular case of modelling species distribution, providing these latter methods are correctly applied. They also noted that the best method would depend on the aims of the study. When models are intended to be explanatory, any of the three approaches compared might be suitable, since all produced good overall fit to the data, but when there exist complex or non-linear influences on species distribution, the ANN may well turn out to be advantageous.

In spite of all these considerations, and provided that enough information is available, it is not possible that a multiple regression outperforms an ANN because if a process is inherently linear, an ANN is as effective as a linear model although it may take more data to be properly generalized (Palmer et al., 2009). When ANNs were not found to perform better than linear methods it was most probably due to non-optimal training strategies, ANN architectures or data-limited situations.

Haralabous \& Georgakarakos (1996) reported that comparing ANNs and DA is not straightforward, because an ANN can only be tested on a subset of training-free cases, while DA can be acceptably tested on the whole dataset. However, this is not exactly correct because the performance of DA cannot be tested without an independent test set. The accuracy of DA can be inferred according to the underlying statistics, but these inferences rely on several assumptions that are probably not met in real world applications (e.g. multi-normality). Consequently, a proper comparison should take a single subset of the data to train the ANN and DA, and then a separate subset to test both methods (Palmer et al., 2009). However, this would require having a sufficiently large number of cases to obtain enough examples in each subset, which is not usual in environmental sciences where sampling programs are costly. 


\section{Multilayer perceptron (MLP)}

The MLP is a supervised ANN which architecture is defined by highly interconnected neurons (units or nodes) that process information in parallel along three successive layers (Fig. 2). The input layer contains as many neurons as independent variables or descriptors used to predict the dependent variables, which in turn constitute the output layer. The third layer, called the hidden layer, is situated between the input and output layers and its number of layers/neurons is an important parameter since it optimizes the performance of the ANN. Neurons from one layer are interconnected to all neurons of neighbouring layers, but no connections are established within a layer or feedback connection. Training any type of supervised ANN consists in using a training dataset to adjust the connection weights in order to minimize the error between observed and predicted values. Once the connections have been established by training they remain fixed in the hidden layer and the ANN can be used for testing. After the network has been trained it should be able to correctly classify patterns that are different from those used during the training phase.

Since the MLP was first used in ecological studies (Komatsu et al., 1994; Lek et al., 1995), the network has been extensively implemented in diverse fields (Park \& Chon, 2007). A good deal of examples (39 cases) of applications in marine and freshwater ecology is shown in Table 1. Most studies used the predictability capabilities of MLPs to infer some dependent variable from a set of environmental variables (29 cases). This dependent variable was generally an index of the quantity of individuals of a certain species (16 cases) such as the abundance, biomass or density or, to a lesser extent, the species occurrence (presence/absence; 7 cases). In other cases the dependent variable referred to community indexes (species richness; 4 cases).

In the overall set of papers the number of input and output neurons ranged between 2-51 and 1-27 respectively. An output layer with a single neuron was by far the most usual network architecture (28 cases), representing this single output the value to be predicted by the MLP for a single species (e.g. abundance, biomass, species richness). In other cases, the MLP was used to predict those values for a set of species. Recknagel et al. (1997), for instance, predicted the abundance of 10 algae species from four different lakes using different sets of environmental variables (7, 10 and 11). Joy \& Death (2004) predicted the occurrence of 14 species of fish and crustaceans taking into account up to 31 driving variables. Similarly, Olden (2003) predicted the occurrence of 27 fishes considering 9 physical variables, whereas Olden et al. (2006) used 24 variables to infer the occurrence of 16 fish species.

Other applications in aquatic ecology different from the prediction of species abundances or occurrences are reported in this paragraph. In two cases the MLP has been used to determine the age at maturation of fish species from annual growth layers in scales or otoliths (Engelhard et al., 2003; Engelhard \& Heino, 2004). Ozesmi \& Ozesmi (1999) predicted the nesting probability of two riverine bird species using 6 environmental variables. The MLP has also been used to identify three different fish species from 25 variables corresponding to the main school descriptors (Haralabous \& Georgakarakos, 1996). Power et al. (2005) made use of MLP to classify a marine fish species according to the three different fisheries from which it was harvested using as predictors the abundance of different sets of parasites (3-6). Dreyfus-Leon (1999) built a model to mimic the search behaviour of fishermen with two MLPs to cope with two separate decision-making processes in fishing activities. One MLP (20 input neurons, 16 output neurons) dealt with decisions to stay or move to new fishing grounds and the other one was constructed to finding prey within the fishing areas (9 inputs, 3 outputs). 


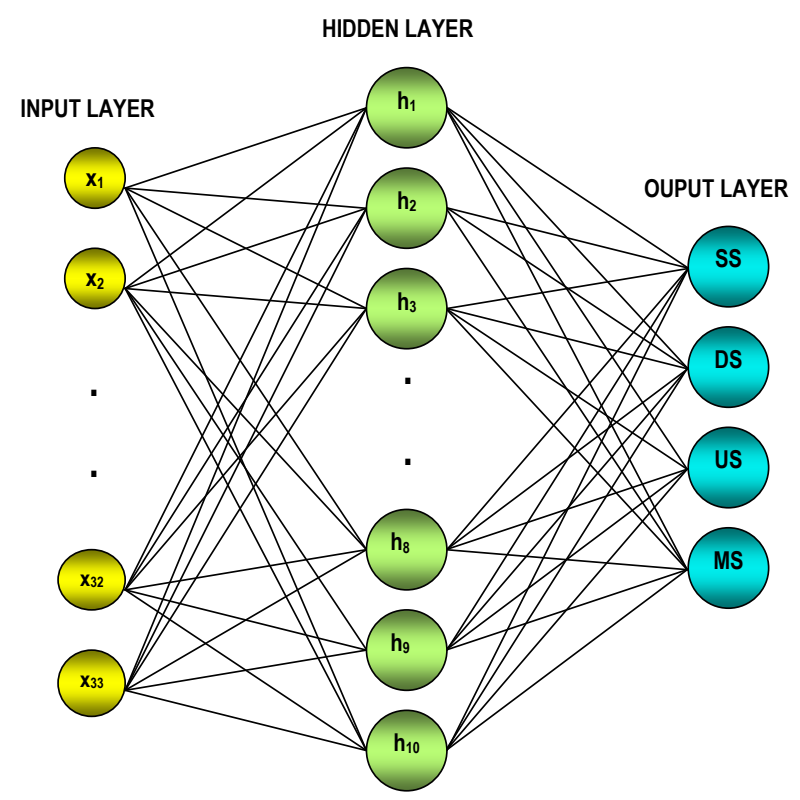

Fig. 2. Scheme of the architecture of a multilayer perceptron (MLP). The example was taken from Palmer et al. (2009), who used the MLP to infer the fishing tactics used by fishermen in their daily trips, taking as predictors the species composition present in the landings statistics. The figure represents a three-layered MLP with 10 neurons in the hidden layer and 33 neurons in the input layer corresponding to the landings of the 33 most important commercial species. The 4 nodes in the output layer are the 4 different fishing tactics to be predicted.

\section{Self-organizing map (SOM)}

The SOMs, also referred to as Kohonen network, are unsupervised ANNs that approximates the probability density function of the input data to display the data sets in a more comprehensible representation form (Kohonen, 2001). In terms of grouping the input data, the SOM is equivalent to conventional multivariate methods such as principal component analysis; it maps the multidimensional data space of complex data sets on two or a few more dimensions, preserving the existing topology as much as possible (Chon et al., 1996). The description that follows on the SOM functioning is based on the book of Lek et al. (2005). The SOM consists exclusively of two layers, the input and output layers, connected by weights that give the connection intensity; the outputs are usually arranged into two dimensional grids on a hexagonal lattice for better visualization (Fig. 3). When an input vector is sent through the network, each neuron in the network computes the distance between the weight vector and the input vector. Among all the output neurons, the one having the minimum distance between the weight and input vectors is chosen. The weights of both this winner neuron and its neighbouring neurons are then updated using the SOM algorithm to further reduce the distance between the weight and the input vector. The training is usually done in two phases: a rough training for ordering based on a large 
neighbourhood radius, followed by fine tuning with a small radius. As a result, the network is trained to classify the input vectors according to the weight vectors that are closest to them. Given that there are not still boundaries between clusters in the trained SOM map, it has to be subdivided into different groups according to the similarity of the weight vectors of the neurons. To analyse the contribution of variables to clusters, each input variable calculated during the training process is visualised in each neuron of the trained SOM in grey scale. The resulting clusters can outperform the results obtained using conventional classification methods, although there is the drawback that the size and shape of the map have to be fixed in advance.

Since Chon et al. (1996) first applied the SOM to patterning benthic communities, it has became the most popular unsupervised neural network in aquatic ecology applications for classification and patterning purposes (Park \& Chon, 2007). In most cases the SOM has been used to classify sampling sites according to different environmental variables or faunal assemblages from their species composition. Jeong et al. (2008b), for instance, classified the different habitats present in a lagoon from a set of 21 limnological characteristics, whereas Cho

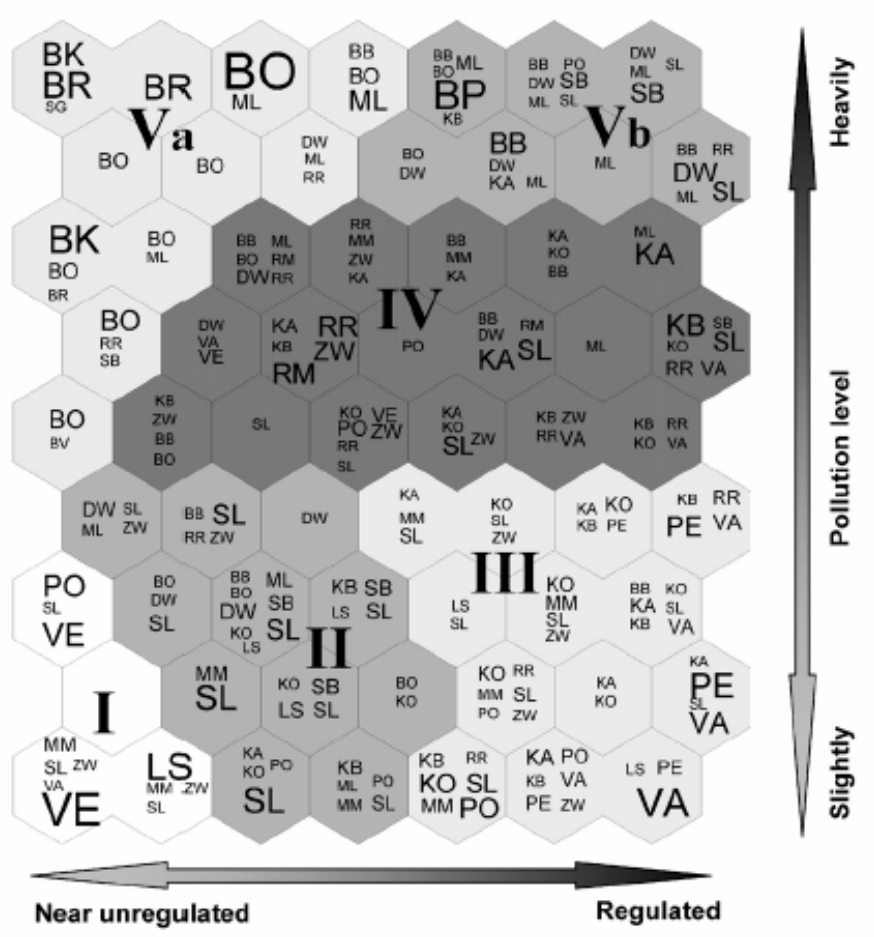

Fig. 3. Example of an output of a two dimensional hexagonal lattice obtained using a selforganizing map (SOM). The figure comes from Park et al. (2003a), who used the SOM to classify sampling sites with different environmental variables. The Latin numbers (I-V) represent different clusters, and the acronyms in the hexagonal units represent different water types. The font size of the acronym is proportional to the number of sampling sites in the water types in the range of 1-18 samples. 
et al. (2009) characterized the habitat preferences of a river otter species taking into account several environmental variables. Song et al. (2006) used the SOM with two different objectives: first to define hydro-morphological patterns of the sampling sites based on four environmental variables, and then to reveal temporal changes in the macro-invertebrate communities inhabiting the sites clustered by SOM. Concerning the classification of faunal communities, the SOM has been mainly used to pattern invertebrate (Chon et al., 1996; Cereghino et al., 2001; Park et al., 2006) and fish (Brosse et al., 2001; Hyun et al., 2005) assemblages. In an original paper, Park et al. (2006) used SOM to patternize benthic macro-invertebrate communities in terms of exergy, which is a measure of the free energy of a system and it is used as an ecological indicator. Hyun et al. (2005) used the SOM to pattern temporal variations in longterm fisheries data (1954-2001) according to the 30 commercially most important species; five clusters were identified corresponding to different time periods reflecting environmental and economic forcings on fish catch. Other SOM applications include the study of the genetic population structure of a sturgeon species (Zhu et al., 2006) and the identification of characteristic patterns from sea level differences using a seven-year time series of satellitederived data (Hardman-Mountford et al., 2003; Fig. 4). Further SOM applications, in combination with other neural network types, are reviewed in the following section.

In most cases, the ecological studies dealing with SOM applications manage complex, large data matrices. The results of all these works agree that the SOM is a powerful tool to extract information from such complex datasets which outperforms conventional approaches used previously in ecology for patterning purposes (e.g. principal component analysis).

\section{Combined networks}

Although ANNs are mainly used for prediction (e.g. MLP) or classification (e.g. SOM), there are also networks performing both functions at the same time. One example used in some ecological applications is the counter-propagation network $(\mathrm{CPN})$, which consists of unsupervised and supervised learning algorithms to classify input vectors and predict output values. The CPN, which name alludes to the counter-flow of data through the network with data flowing inward from both sides, functions as a statistically optimal self-adapting look-up table (Hecht-Nielsen, 1988). Park et al. (2003b) applied a CPN to predict species richness and diversity index of benthic macro-invertebrate communities using 34 environmental variables. The trained CPN was useful for finding the corresponding values between environmental variables and community indices and displayed a high accuracy in the prediction process.

In some cases, researchers simply use two different networks in sequential steps for classification purposes first, followed by prediction. Chon et al. (2000) analysed patterns of temporal variation in community dynamics of benthic macro-invertebrates by combining two unsupervised ANNs, the adaptive resonance theory (ART) and the SOM. Park et al. (2004) also used the combination of ART and SOM to assess benthic communities in stream ecosystems, first using the SOM to reduce the dimension of the community data and secondly the ART to further classify the groups in different scale. Park et al. (2003a) used the SOM to classify sampling sites using species richness of aquatic insect orders and afterwards applied the MLP to predict the arrangements obtained using a set of environmental variables. Gevrey et al. (2004) used the SOM to classify samples according to their diatom composition, and then MLP to predict these assemblages using environmental characteristics of each sample. Similarly, Tison et al. (2007) classified diatom samples using the SOM and then predicted the community types with different environmental variables through a MLP. 


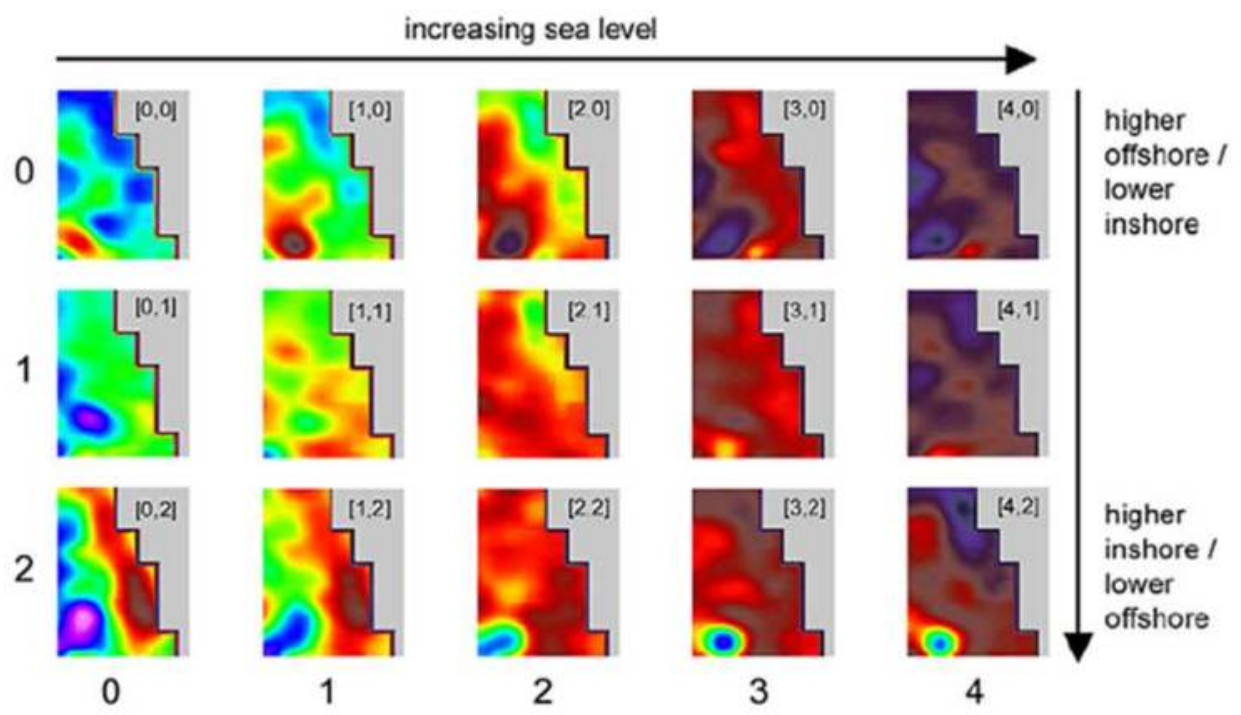

Sea Level Difference $(\mathrm{cm})$

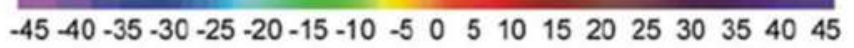

Fig. 4. The SOM of sea level differences obtained by Hardman-Mountford et al. (2003) using remote sensing data. The 15 patterns in a 5 by 3 array, where the land is shown in grey, correspond to different time periods with contrasting oceanographic scenarios.

\section{Other types of ANNs}

Apart from MLP and SOM there are still very few examples of applications of other types of ANNs in ecological studies. We have only found the use of four different types of networks in our review: functional neural network (FNN), Bayesian regularized back-propagation neural network (BRBPNN), temporal autoregressive recurrent neural network (TARNN) and generalized regression neural network (GRNN).

Iglesias et al. (2004) applied the FNN, a type of network in which the weights of the neurons are substituted by a set of functions, to predict the catches of two pelagic fish species taken as independent variables a set of oceanographic parameters obtained from remote sensors. The results of this study showed that functional networks considerably improved the predictions obtained using MLP. Xu et al. (2005) used the BRBPNN to predict chlorophyll trends in a lake; the advantage of this model is that it can automatically select the regularization parameters and integrate the characteristics of high convergent rate of traditional back-propagation neural networks and prior information of Bayesian statistics. Jeong et al. (2008a) developed a TARNN model to predict time-series changes of phytoplankton dynamics in a regulated river ecosystem. The TARNN algorithms were found to be an alternative solution to overcome the increasing size and structural complexity of the models used in freshwater ecology. Palmer et al. (2009) used the GRNN, together with MLP and DA, to predict fishing tactics from daily landing data. In this application, the GRNN, which is a type of ANN having the same number of neurons as there are cases in the training data set, outperformed both the MLP and DA. 


\section{Conclusion}

The study of the highly complex structure and dynamics of ecological systems demands appropriate powerful tools such as ANNs. This is especially relevant nowadays, when the scientific community handles a lot of bulky databases and has to cope with global environmental threats that require urgent international attention. The purpose of this review is twofold. First, to familiarize ANNs users from other scientific disciplines, such as the ones covered in this book, with the use that ecologists make of these methods. Second, introduce ecologists unfamiliar with the ANNs to the capabilities of these tools and show them the palette of practical applications currently available in the domain of the aquatic ecology. Although the majority of ecologists lack the theoretical and computational background needed to implement these approaches (Fielding, 1999), they can take advantage of the userfriendly software that is being rapidly developed during recent years (Olden et al., 2008). One important drawback is, however, the fact that ANN modelling is a very active research area and the dissemination of useful information for practitioners constitutes one of the greatest challenges facing ANNs users (Maier \& Dandy, 2000). By contrast, these approaches are flexible and readily combinable with other methods (Lek et al. 2005; Recknagel 2006), which would allow ecologists to develop models of increasing complexity as requires the analysis of ecological systems.

According to Pascual \& Dunne (2006), understanding the ecology and mathematics of ecological networks is central to understanding the fate of biodiversity and ecosystems in response to perturbations. Knowing the network structure is essential to understand the properties of the network and the use of ANNs in ecological models constitutes a first step towards this understanding. We hope our review could awake the interest of ecologists in ANN modelling and maybe to help them with the use of these approaches in their studies on aquatic ecology.

\section{Acknowledgements}

The image of Figure 1a was produced with FoodWeb3D, written by R.J. Williams and provided by the Pacific Ecoinformatics and Computational Ecology Lab (www.foodwebs.org, Yoon et al., 2004). Figures 1b, 2, 3 and 4 were reproduced with permission. Figure $1 \mathrm{c}$ was reproduced with permission from http://technology.desktopnexus.com/wallpaper/48950/.

\section{References}

Baran, P., Lek, S., Delacoste, M. \& Belaud, A. (1996). Stochastic models that predict trout population density or biomass on a mesohabitat scale. Hydrobiologia, 337, 1-3, 1-9, ISSN: 0018-8158

Bishop, C.M. (1995). Neural networks for pattern recognition, Clarendon Press, ISBN-10: 0198538642, Oxford

Brosse, S., Giraudel, J.L. \& Lek, S. (2001). Utilisation of non-supervised neural networks and principal component analysis to study fish assemblages. Ecological Modelling, 146, 13, 159-166, ISSN: 0304-3800

Brosse, S., Guegan, J.F., Tourenq, J.N. \& Lek, S. (1999). The use of artificial neural networks to assess fish abundance and spatial occupancy in the littoral zone of a mesotrophic lake. Ecological Modelling, 120, 2-3, 299-311, ISSN: 0304-3800 
Burnham, K.P. \& Anderson, D.R. (2002). Model selection and multimodel inference: a practical information-theoretic approach, Springer, ISSN-10: 0387953647, New York

Cereghino, R., Giraudel, J.L. \& Compin, A. (2001). Spatial analysis of stream invertebrates distribution in the Adour-Garonne drainage basin (France), using Kohonen self organizing maps. Ecological Modelling, 146, 1-3, 167-180, ISSN: 0304-3800

Cho, H.S., Choi, K.H., Lee, S.D. \& Park, Y.S. (2009). Characterizing habitat preference of Eurasian river otter (Lutra lutra) in streams using a self-organizing map. Limnology, 10, 3, 203-213, ISSN: 1439-8621

Chon, T.S., Park, Y.S., Moon, K.H. \& Cha, E.Y. (1996). Patternizing communities by using an artificial neural network. Ecological Modelling, 90, 1, 69-78, ISSN: 0304-3800

Chon, T.S., Park, Y.S. \& Park, J.H. (2000). Determining temporal pattern of community dynamics by using unsupervised learning algorithms. Ecological Modelling, 132, 1-2, 151-166, ISSN: 0304-3800

Dimopoulos, I., Chronopoulos, J., Chronopoulou-Sereli, A. \& Lek, S. (1999). Neural network models to study relationships between lead concentration in grasses and permanent urban descriptors in Athens city (Greece). Ecological Modelling, 120, 2-3, 157-165, ISSN

Dreyfus-Leon, M.J. (1999). Individual-based modelling of fishermen search behaviour with neural networks and reinforcement learning. Ecological Modelling, 120, 2-3, 287-297, ISSN: 0304-3800

Engelhard, G.H., Dieckmann, U. \& Godo, O.R. (2003). Age at maturation predicted from routine scale measurements in Norwegian spring-spawning herring (Clupea harengus) using discriminant and neural network analyses. ICES Journal of Marine Science, 60, 2, 304-313, ISSN: 1054-3139

Engelhard, G.H. \& Heino, M. (2004). Maturity changes in Norwegian spring-spawning herring before, during, and after a major population collapse. Fisheries Research, 66, 2-3, 299-310, ISSN: 0165-7836

Fang, W.T., Chu, H.J. \& Cheng, B.Y. (2009). Modeling waterbird diversity in irrigation ponds of Taoyuan, Taiwan using an artificial neural network approach. Paddy and Water Environment, 7, 3, 209-216, ISSN: 1611-2490

Fielding, A.H. (1999). Machine learning methods for ecological applications, Klumer Academic Publishers, ISBN-10: 0412841908, Massachusetts

Garson, G.D. (1991). Interpreting neural network connection weights. Artificial Intelligence Expert, 6, 47-51, ISSN: 0004-3702

Gevrey, M., Dimopoulos, I. \& Lek, S. (2006). Two-way interaction of input variables in the sensitivity analysis of neural network models. Ecological Modelling, 195, 1-2, 43-50, ISSN: 0304-3800

Gevrey, M., Dimopoulos, L. \& Lek, S. (2003). Review and comparison of methods to study the contribution of variables in artificial neural network models. Ecological Modelling, 160, 3, 249-264, ISSN: 0304-3800

Gevrey, M., Rimet, F., Park, Y.S., Giraudel, J.L., Ector, L. \& Lek, S. (2004). Water quality assessment using diatom assemblages and advanced modelling techniques. Freshwater Biology, 49, 2, 208-220, ISSN: 0046-5070

Goh, A.T.C. (1995). Back-propagation neural networks for modelling complex systems. Artificial Intelligence in Engineering, 9, 143-151, ISSN: 0954-1810 
Gutierrez-Estrada, J.C., Yanez, E., Pulido-Calvo, I., Silva, C., Plaza, F. \& Borquez, C. (2009). Pacific sardine (Sardinops sagax, Jenyns 1842) landings prediction. A neural network ecosystemic approach. Fisheries Research, 100, 2, 116-125, ISSN: 0165-7836

Haralabous, J. \& Georgakarakos, S. (1996). Artificial neural networks as a tool for species identification of fish schools. ICES Journal of Marine Science, 53, 2, 173-180, ISSN: 1054-3139

Hardman-Mountford, N.J., Richardson, A.J., Boyer, D.C., Kreiner, A. \& Boyer, H.J. (2003). Relating sardine recruitment in the Northern Benguela to satellite-derived sea surface height using a neural network pattern recognition approach. Progress in Oceanography, 59, 2-3, 241-255, ISSN: 0079-6611

Hecht-Nielsen, R. (1988). Applications of counterpropagation networks. Neural Networks, 1, 2, 131-139, ISSN: 0893-6080

Hopfield, J.J. (1982). Neural networks and physical systems with emergent collective computational abilities. Proceedings of the National Academy of Sciences of the United States of America-Biological Sciences, 79, 8, 2554-2558, ISSN: 0273-1134

Hyun, K., Song, M.Y., Kim, S. \& Chon, T.S. (2005). Using an artificial neural network to patternize long-term fisheries data from South Korea. Aquatic Sciences, 67, 3, 382389, ISSN: 1015-1621

Ibarra, A.A., Gevrey, M., Park, Y.S., Lim, P. \& Lek, S. (2003). Modelling the factors that influence fish guilds composition using a back-propagation network: Assessment of metrics for indices of biotic integrity. Ecological Modelling, 160, 3, 281-290, ISSN: 0304-3800

Iglesias, A., Arcay, B., Cotos, J.M., Taboada, J.A. \& Dafonte, C. (2004). A comparison between functional networks and artificial neural networks for the prediction of fishing catches. Neural Computing and Applications, 13, 1, 24-31, ISSN: 0941-0643

Jeong, K.S., Kim, D.K., Jung, J.M., Kim, M.C. \& Joo, G.J. (2008a). Non-linear autoregressive modelling by temporal recurrent neural networks for the prediction of freshwater phytoplankton dynamics. Ecological Modelling, 211, 3-4, 292-300, ISSN: 0304-3800

Jeong, K.S., Kim, D.K., Pattnaik, A., Bhatta, K., Bhandari, B. \& Joo, G.J. (2008b). Patterning limnological characteristics of the Chilika lagoon (India) using a self-organizing map. Limnology, 9, 3, 231-242, ISSN: 1439-8621

Joy, M.K. \& Death, R.G. (2004). Predictive modelling and spatial mapping of freshwater fish and decapod assemblages using GIS and neural networks. Freshwater Biology, 49, 8, 1036-1052, ISSN: 0046-5070

Kohonen, T. (2001). Self-organizing maps. Springer, ISBN: 3-540-67921-9, New York

Komatsu, T., Aoki, I., Mitani, I. \& Ishii, T. (1994). Prediction of the catch of Japanese sardine larvae in Sagami Bay using a neural network. Fisheries Science, 60, 4, 385-391, ISSN: 0919-9268

Lae, R., Lek, S. \& Moreau, J. (1999). Predicting fish yield of African lakes using neural networks. Ecological Modelling, 120, 2-3, 325-335, ISSN: 0304-3800

Lek, S., Belaud, A., Baran, P., Dimopoulos, I. \& Delacoste, M. (1996a). Role of some environmental variables in trout abundance models using neural networks. Aquatic Living Resources, 9, 1, 23-29, ISSN: 0990-7440

Lek, S., Belaud, A., Dimopoulos, I., Lauga, J. \& Moreau, J. (1995). Improved estimation, using neural networks, of the food consumption of fish populations. Marine and Freshwater Research, 46, 8, 1229-1236, ISSN: 1323-1650 
Lek, S., Delacoste, M., Baran, P., Dimopoulos, I., Lauga, J. \& Aulagnier, S. (1996b). Application of neural networks to modelling nonlinear relationships in ecology. Ecological Modelling, 90, 1, 39-52, ISSN: 0304-3800

Lek, S. \& Guegan, J.F. (2000). Artificial neural networks: application to ecology and evolution. Springer, ISSN-10: 3540669213, New York

Lek, S., Scardi, M., Verdonschot, P.F.M., Descy, J.P. \& Park, Y.S. (2005). Modelling community structure in freshwater ecosystems. Springer, ISBN-10: 3540239405, New York

Letunic, I., Yamada, T., Kanehisa, M. \& Bork, P. (2008). iPath: interactive exploration of biochemical pathways and networks. Trends in Biochemical Sciences, 33, 3, 101-103, ISSN: 0968-0004

Maier, H.R. \& Dandy, G.C. (2000). Neural networks for the prediction and forecasting of water resources variables: a review of modelling issues and applications. Environmental Modelling \& Software, 15, 1, 101-124, ISSN: 1364-8152

Maier, H.R. \& Dandy, G.C. (2001). Neural network based modelling of environmental variables: A systematic approach. Mathematical and Computer Modelling, 33, 6-7, 669682, ISSN: 0895-7177

Manel, S., Dias, J.M. \& Ormerod, S.J. (1999). Comparing discriminant analysis, neural networks and logistic regression for predicting species distributions: a case study with a Himalayan river bird. Ecological Modelling, 120, 2-3, 337-347, ISSN: 0304-3800

Maravelias, C.D., Haralabous, J. \& Papaconstantinou, C. (2003). Predicting demersal fish species distributions in the Mediterranean Sea using artificial neural networks. Marine Ecology Progress Series, 255, 249-258, ISSN: 0171-8630

Mastrorillo, S., Lek, S., Dauba, F. \& Belaud, A. (1997). The use of artificial neural networks to predict the presence of small-bodied fish in a river. Freshwater Biology, 38, 2, 237246, ISSN: 0046-5070

McCulloch, W.S. \& Pitts, W. (1943). A logical calculus of the ideas imminent in nervous activity. Bulletin of Mathematical Biophysics, 5, 115-133, ISSN: 0007-4985

Olden, J.D. (2000). An artificial neural network approach for studying phytoplankton succession. Hydrobiologia, 436, 1-3, 131-143, ISSN: 0018-8158

Olden, J.D. (2003). A species-specific approach to modeling biological communities and its potential for conservation. Conservation Biology, 17, 3, 854-863, ISSN: 0888-8892

Olden, J.D. \& Jackson, D.A. (2002). Illuminating the "black box": a randomization approach for understanding variable contributions in artificial neural networks. Ecological Modelling, 154, 1-2, 135-150, ISSN: 0304-3800

Olden, J.D., Joy, M.K. \& Death, R.G. (2006). Rediscovering the species in community-wide predictive modeling. Ecological Applications, 16, 4, 1449-1460, ISSN: 1051-0761

Olden, J.D., Lawler, J.J. \& Poff, N.L. (2008). Machine learning methods without tears: A primer for ecologists. Quarterly Review of Biology, 83, 2, 171-193, ISSN: 0033-5770

Ozesmi, S.L. \& Ozesmi, U. (1999). An artificial neural network approach to spatial habitat modelling with interspecific interaction. Ecological Modelling, 116, 1, 15-31, ISSN: 0304-3800

Ozesmi, S.L., Tan, C.O. \& Ozesmi, U. (2006). Methodological issues in building, training, and testing artificial neural networks in ecological applications. Ecological Modelling, 195, 1-2, 83-93, ISSN: 0304-3800

Palmer, M., Quetglas, A., Guijarro, B., Moranta, J., Ordines, F. \& Massuti, E. (2009). Performance of artificial neural networks and discriminant analysis in predicting 
fishing tactics from multispecific fisheries. Canadian Journal of Fisheries and Aquatic Sciences, 66, 224-237, ISSN: 0706-652X

Park, Y.S., Cereghino, R., Compin, A. \& Lek, S. (2003b). Applications of artificial neural networks for patterning and predicting aquatic insect species richness in running waters. Ecological Modelling, 160, 3, 265-280, ISSN: 0304-3800

Park, Y.S. \& Chon, T.S. (2007). Biologically-inspired machine learning implemented to ecological informatics. Ecological Modelling, 203, 1-2, 1-7, ISSN: 0304-3800

Park, Y.S., Chon, T.S., Kwak, I.S. \& Lek, S. (2004). Hierarchical community classification and assessment of aquatic ecosystems using artificial neural networks. Science of the Total Environment, 327, 1-3, 105-122, ISSN: 0048-9697

Park, Y.S., Lek, S., Scardi, M., Verdonschot, P.F.M. \& Jorgensen, S.E. (2006). Patterning exergy of benthic macroinvertebrate communities using self-organizing maps. Ecological Modelling, 195, 1-2, 105-113, ISSN: 0304-3800

Park, Y.S., Verdonschot, P.F.M., Chon, T.S. \& Lek, S. (2003a). Patterning and predicting aquatic macroinvertebrate diversities using artificial neural network. Water Research, 37, 8, 1749-1758, ISSN: 0043-1354

Pascual, M. \& Dunne, J.A. (2006). From small to large ecological networks in a dynamic world, In Ecological Networks: Linking Structure to Dynamics in Food Webs, Pascual M. \& Dunne A. (Editors), 3-24, Oxford University Press, ISBN-10: 0195188160, Oxford

Picton, P.D. (2000). Neural networks. Palgrave Macmillan, ISBN-10: 033380287X, New York

Pitts, W. \& McCulloch, W.S. (1947). How we know universals: the perception of auditory and visual forms. Bulletin of Mathematical Biophysics, 9, 3, 127-147, ISSN: 0007-4985

Power, A.M., Balbuena, J.A. \& Raga, J.A. (2005). Parasite infracommunities as predictors of harvest location of bogue (Boops boops L.): a pilot study using statistical classifiers. Fisheries Research, 72, 2-3, 229-239, ISSN: 0165-7836

Recknagel, F. (2006). Ecological Informatics: scope, techniques and applications, Springer, ISBN10: 3540283838, New York

Recknagel, F., French, M., Harkonen, P. \& Yabunaka, K. (1997). Artificial neural network approach for modelling and prediction of algal blooms. Ecological Modelling, 96, 1-3, 11-28, ISSN: 0304-3800

Reyjol, Y., Lim, P., Belaud, A. \& Lek, S. (2001). Modelling of microhabitat used by fish in natural and regulated flows in the river Garonne (France). Ecological Modelling, 146, 1-3, 131-142, ISSN: 0304-3800

Rumelhart, D.E., Hinton, G.E. \& Williams, R.J. (1986). Learning representations by backpropagating errors. Nature, 323, 6088, 533-536, ISSN: 0028-0836

Sarle, W.S. (1997). Neural network FAQ, periodic posting to the Usenet newsgroup comp.ai.neural-nets. Available from ftp.sas.com/pub/neural/FAQ.html

Scardi, M. (1996). Artificial neural networks as empirical models for estimating phytoplankton production. Marine Ecology Progress Series, 139, 289-299, ISSN: 01718630

Solé, R. \& Goodwin, B. (2000). Signs of life: how complexity pervades biology, Basic Books, ISBN10: 0465019285, New York

Song, M.Y., Park, Y.S., Kwak, I.S., Woo, H. \& Chon, T.S. (2006). Characterization of benthic macroinvertebrate communities in a restored stream by using self-organizing map. Ecological Informatics, 1, 3, 295-305, ISSN: 1574-9541 
Stern, H.S. (1996). Neural networks in applied statistics. Technometrics, 38, 3, 205-214, ISSN: 0040-1706

Strogatz, S.H. (2001). Exploring complex networks. Nature, 410, 6825, 268-276, ISSN: 00280836

Suryanarayana, I., Braibanti, A., Rao, R.S., Ramam, V.A., Sudarsan, D. \& Rao, G.N. (2008). Neural networks in fisheries research. Fisheries Research, 92, 2-3, 115-139, ISSN: 0165-7836

Tison, J., Park, Y.S., Coste, M., Wasson, J.G., Rimet, F., Ector, L. \& Delmas, F. (2007). Predicting diatom reference communities at the French hydrosystem scale: a first step towards the definition of the good ecological status. Ecological Modelling, 203, 12, 99-108, ISSN: 0304-3800

Xu, M., Zeng, G.M., Xu, X.Y., Huang, G.H., Sun, W. \& Jiang, X.Y. (2005). Application of bayesian regularized BP neural network model for analysis of aquatic ecological data: a case study of chlorophyll-a prediction in Nanzui water area of Dongting Lake. Journal of Environmental Sciences-China, 17, 6, 946-952, ISSN: 10010742

Yoon, I., Williams, R.J., Levine, E., Yoon, S., Dunne, J.A. \& Martinez, N.D. (2004). Webs on the Web (WoW): 3D visualization of ecological networks on the WWW for collaborative research and education. Proceedings of the IS\&T/SPIE Symposium on Electronic Imaging, Visualization and Data Analysis, 5295: 124-132,

Zhu, B., Zhao, N., Shao, Z.J., Lek, S. \& Chang, J.B. (2006). Genetic population structure of Chinese sturgeon (Acipenser sinensis) in the Yangtze River revealed by artificial neural network. Journal of Applied Ichthyology, 22, 82-88, ISSN: 0175-8659 


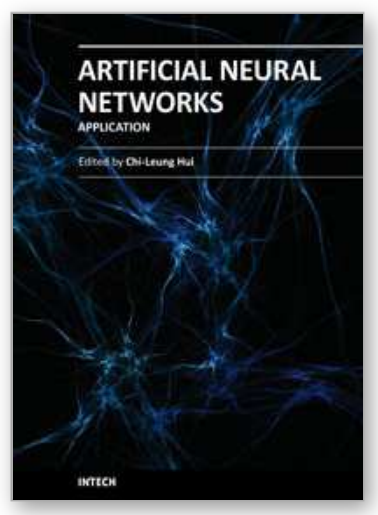

\author{
Artificial Neural Networks - Application \\ Edited by Dr. Chi Leung Patrick Hui
}

ISBN 978-953-307-188-6

Hard cover, 586 pages

Publisher InTech

Published online 11, April, 2011

Published in print edition April, 2011

This book covers 27 articles in the applications of artificial neural networks (ANN) in various disciplines which includes business, chemical technology, computing, engineering, environmental science, science and nanotechnology. They modeled the ANN with verification in different areas. They demonstrated that the ANN is very useful model and the ANN could be applied in problem solving and machine learning. This book is suitable for all professionals and scientists in understanding how ANN is applied in various areas.

\title{
How to reference
}

In order to correctly reference this scholarly work, feel free to copy and paste the following:

Antoni Quetglas, Francesc Ordines and Beatriz Guijarro (2011). The Use of Artificial Neural Networks (ANNs) in Aquatic Ecology, Artificial Neural Networks - Application, Dr. Chi Leung Patrick Hui (Ed.), ISBN: 978-953307-188-6, InTech, Available from: http://www.intechopen.com/books/artificial-neural-networks-application/theuse-of-artificial-neural-networks-anns-in-aquatic-ecology

\section{INTECH}

open science | open minds

\section{InTech Europe}

University Campus STeP Ri

Slavka Krautzeka 83/A

51000 Rijeka, Croatia

Phone: +385 (51) 770447

Fax: +385 (51) 686166

www.intechopen.com

\section{InTech China}

Unit 405, Office Block, Hotel Equatorial Shanghai

No.65, Yan An Road (West), Shanghai, 200040, China

中国上海市延安西路65号上海国际贵都大饭店办公楼 405 单元

Phone: +86-21-62489820

Fax: +86-21-62489821 
(C) 2011 The Author(s). Licensee IntechOpen. This chapter is distributed under the terms of the Creative Commons Attribution-NonCommercialShareAlike-3.0 License, which permits use, distribution and reproduction for non-commercial purposes, provided the original is properly cited and derivative works building on this content are distributed under the same license. 